\title{
ACE2 Down-Regulation May Act as a Transient Molecular Disease Causing RAAS Dysregulation and Tissue Damage in the Microcirculatory Environment Among COVID-19 Patients
}

\author{
Simone Gusmão Ramos, ${ }^{*}$ Bruna Amanda da Cruz Rattis, ${ }^{*}$ Giulia Ottaviani, ${ }^{\dagger}$ Mara Rubia Nunes Celes, ${ }^{* \ddagger}$ and Eliane Pedra Dias
}

From the Department of Pathology and Forensic Medicine, * Ribeirão Preto Medical School, University of São Paulo, Ribeirão Preto, São Paulo, Brazil; the Centro di Ricerca Lino Rossi, ${ }^{\dagger}$ Anatomic Pathology MED-08, Università degli Studi di Milano, Milan, Italy; the Department of Bioscience and Technology, ${ }^{\ddagger}$ Institute of Tropical Pathology and Public Health, Federal University of Goias, Goiania, Goias, Brazil; and the Department of Pathology, ${ }^{\S}$ Faculty of Medicine, Fluminense Federal University, Niteroi, Rio de Janeiro, Brazil

Accepted for publication April 22, 2021.

Address correspondence to Simone Gusmão Ramos, M.D., Ph.D., Department of Pathology and Forensic Medicine,

Ribeirão Preto Medical School, University of São Paulo, 14049900, Ribeirão Preto, São Paulo, Brazil. E-mail: sgramos@fmrp. usp.br.

\begin{abstract}
Severe acute respiratory syndrome coronavirus 2, the etiologic agent of coronavirus disease 2019 (COVID-19) and the cause of the current pandemic, produces multiform manifestations throughout the body, causing indiscriminate damage to multiple organ systems, particularly the lungs, heart, brain, kidney, and vasculature. The aim of this review is to provide a new assessment of the data already available for COVID-19, exploring it as a transient molecular disease that causes negative regulation of angiotensin-converting enzyme 2, and consequently, deregulates the renin-angiotensin-aldosterone system, promoting important changes in the microcirculatory environment. Another goal of the article is to show how these microcirculatory changes may be responsible for the wide variety of injury mechanisms observed in different organs in this disease. The new concept of COVID-19 provides a unifying pathophysiological picture of this infection and offers fresh insights for a rational treatment strategy to combat this ongoing pandemic. (Am J Pathol 2021, 191: 1154-1164; https://doi.org/ 10.1016/j.ajpath.2021.04.010)
\end{abstract}

Even a full year after the initial outbreak and spread of severe acute respiratory syndrome coronavirus-2 (SARSCoV-2), its mechanisms of disease are still widely debated. Although the lungs are believed to be the only target organ, other organs and tissues can be affected, leading to a wide variety of clinical conditions in patients with coronavirus disease 2019 (COVID-19). Although the prognosis is favorable in most patients, critical illness, manifested by respiratory distress, thromboembolism, shock, multiorgan failure, and eventually death, has been reported in approximately $5 \%$ of cases. ${ }^{1}$ Several studies have linked this virus to a defective immune response, with excessive cytokine release as a fundamental aspect of the COVID-19 pathogenesis. ${ }^{2}$ However, the way in which this disease causes damage to tissues in various organs is still under investigation.
The current article aims to provide an analysis from experienced pathologists regarding the pathophysiological changes resulting from COVID-19. Herein, it is proposed that SARS-CoV-2 provokes a transient molecular disease involving angiotensin-converting enzyme 2 (ACE2) downregulation and consequent renin-angiotensin-aldosterone system (RAAS) dysregulation, with these phenomena being at least partially responsible for the multifocal tissue

Supported by grants from the Coordenacão de Aperfeicoamento de Pessoal de Nivel Superior (CAPES/Brazil) [no. 88882.378587/2019-01]; the Fundação de Amparo à Pesquisa do Estado de São Paulo (FAPESP/SP/ Brazil) [no. 2012/23649-0]; and the Fundação de Apoio ao Ensino, Pesquisa e Assistência do HCFMRP-USP (FAEPA/Brazil) [ no. 269/2021; no. 272/2021].

Disclosures: None declared. 
damage in the microcirculatory environment and playing a fundamental role in the pathogenesis of this disease.

\section{SARS-CoV-2 Infection and ACE2 Down- Regulation}

Entry into host cells is the first step of viral infection. In humans, coronaviruses gain entry into host cells by way of their transmembrane spike (S) glycoprotein, which comprises $\mathrm{S} 1$ and $\mathrm{S} 2$ subunits. The $\mathrm{S} 1$ subunit is responsible for binding to the host cell receptor, and the $\mathrm{S} 2$ subunit assists with virus-host cell fusion. ${ }^{3}$ SARS-CoV-2 gains access to host cells by engaging the protein ACE2, a transmembrane carboxypeptidase expressed in nearly all human organs and tissues to varying degrees. ${ }^{4}$ ACE2 exists in two forms, a membrane-bound form and a soluble form, and SARS-CoV2 entry into the host cell is mediated by binding of viral $\mathrm{S}$ protein to the membrane-bound form. ${ }^{5}$ SARS-CoV-2 downregulates these receptors by taking advantage of at least two host proteases: type II transmembrane serine protease (ie, TMPRSS2), which facilitates viral ingress by cleaving the $\mathrm{S}$ antigen into $\mathrm{S} 1$ (the active binding site), and disintegrin and metalloproteinase domain-containing protein 17 (ie, ADAM17), which down-regulates ACE2 by spreading it together with the attached virus through blood circulation. ${ }^{6,7}$ Although SARS-CoV also binds to ACE2, SARS-CoV-2 has 10 -fold to 20 -fold greater binding affinity than SARS$\mathrm{CoV}^{8}$ Therefore, regarding the mechanism of infection, what makes SARS-CoV-2 novel (compared with other common respiratory pathogens such as influenza and parainfluenza viruses) is the use of ACE2, a specific protein, as its receptor.

ACE2 is a key modulator of the RAAS, an intricate interlinked system that regulates physiological and pathologic functions of the cardiovascular, renal, and pulmonary systems. $^{9-11}$ Aside from regulating arterial blood pressure, cardiac function, and fluid balance, the RAAS plays a major role in immunity. ${ }^{12}$ Under normal circumstances, ACE2 terminates the action of angiotensin (Ang) I and Ang II by cleaving these peptides into Ang 1-9 and Ang 1-7, respectively. In the absence of ACE2 (due to viral blockade and down-regulation), both Ang I and Ang II accumulate. However, because ACE is not engaged by the virus, the conversion of Ang I to Ang II continues unabated, leading to unopposed accumulation of Ang II. Ang II is the biologically active mediator of effects of the RAAS, whose functions are controlled by two $G$ protein-coupled receptors, Ang II type 1 receptor $\left(\mathrm{AT}_{1} \mathrm{R}\right)$ and Ang II type 2 receptor. ${ }^{9-11}$ Abnormal activation of the Ang II/AT $T_{1} R$ component of RAAS has been implicated in several pathologic conditions, including the development of end-organ damage through the activation of proinflammatory and profibrotic cascades. ${ }^{13}$ Therefore, COVID-19-induced ACE/ACE2 imbalance promoting Ang II upregulation in the microcirculatory environment may favor local inflammation, capillary leakage, a procoagulant state, mitochondrial oxidative damage, reactive oxygen species production, and IL-6 up-regulation, inducing coagulation and an immune response. ${ }^{5,6,14}$ A detailed review of these mechanisms can be found elsewhere. ${ }^{12,15-17}$

\section{Immunothrombosis (Thromboinflammation) and COVID-19}

Immunothrombosis is a consequence of the evolutionarily conserved link between blood coagulation and innate immunity, and it is regarded as a newly revised, crucial element of intravascular immunity that encompasses a wide range of host strategies to detect and protect against pathogens in the vasculature. ${ }^{18,19}$ It is a complex mechanism of host protection against pathogens resulting from the interaction between innate immunity effector systems (eg, monocytes/macrophages, neutrophils, the complement system) and platelets and coagulation factors, favoring the development of microthrombi within the microcirculation. ${ }^{18-20}$ Regardless of the initiating event, the host response to injury and/or pathogen invasion includes the local delivery of active tissue factor, the degradation of endogenous anticoagulants, and the release of neutrophil extracellular traps (NETs) that provide a scaffold procoagulant consisting of DNA, histones, and neutrophil serine proteases. NETosis sequesters platelets in the microcirculation, causing increased fibrin-platelet interactions and the formation of microthrombi. ${ }^{21}$ Ordinarily, combat against the pathogen remains restricted to the intravascular compartment, triggering minimal host parenchymal damage. However, on a large scale, immunothrombosis can be a major biological process fostering the pathologies associated with thrombosis in the microvasculature and promoting tissue damage. 22,23

The mechanisms by which SARS-CoV-2 induces microthrombosis remain incompletely understood. A sequence of events has been proposed, as described here. SARS-CoV-2 can directly invade type II pneumocytes. ${ }^{24,25}$ Infected cells undergo pyroptosis, leading to the release of danger-associated molecular patterns and triggering the release of proinflammatory cytokines and chemokines into the environment. ${ }^{26,27}$ The activated alveolar endothelium then up-regulates the expression of von Willebrand factor and adhesion molecules, including inter-cellular adhesion molecule-1, vitronectin receptor (alpha v beta 3 integrin), $\mathrm{P}$ selectin, and E-selectin, leading to recruitment of platelets and leukocytes and complement activation. ${ }^{25}$ Neutrophils release NETs, causing direct activation of the classical complement pathway. Complement activation potentiates these mechanisms by increasing endothelial and monocyte tissue factor and further platelet activation, and amplifying endothelial inflammation, which increases the production of proinflammatory cytokines from the endothelium. These include the following: IL-1; IL-8; regulated on activation, 
normal T-cell expressed and secreted; IL-6; and monocyte chemoattractant protein- $1 .{ }^{28,29}$ The hypoxic environment can induce hypoxia-inducible factors, which up-regulate endothelial tissue factor expression. These mechanisms ultimately lead to the unchecked generation of thrombin, resulting in thrombus formation. ${ }^{12,30,31}$

Activated platelets and neutrophils releasing NETs are directly linked to thrombosis and inflammation, causing organ damage and increasing mortality in cases of severe COVID-19. ${ }^{21,32}$ Autopsy reports have suggested that COVID-19-induced formation of NETs may contribute to cytokine storms, vascular thrombosis, and acute respiratory distress syndrome. ${ }^{33}$ Although a limited amount of NET formation at inflammatory sites serves to limit blood loss and prevent the spread of pathogens, ${ }^{18,19}$ NET formation in COVID-19 is clearly dysregulated at multiple intravascular sites, leading to rapid occlusion of microvessels. ${ }^{34}$ Therefore, an unfavorable milieu can allow these phenomena to spread uncontrollably in the circulation, promoting multiorgan dysfunction.

\section{Clinical Evidence of Thrombotic Disorders in COVID-19: A Procoagulant Disease}

Since the beginning of the pandemic, COVID-19 was recognized as a hypercoagulatory disease associated with a clinically high prevalence of thromboembolic events. ${ }^{35}$ Increased blood levels of D-dimer, fibrinogen, and fibrin degradation products are frequently reported as useful biomarkers of the severity of disease and predictors of adverse outcomes. ${ }^{36}$ Venous and arterial thrombotic events were seen in up to $30 \%$ of patients treated in the intensive care unit, even with pharmacologic thromboprophylaxis, and were associated with a 5.4-fold increase in the risk of mortality. ${ }^{37}$ An autopsy series of patients with COVID-19 found deep vein thrombosis and pulmonary embolism in $58 \%$ and $73 \%$ of the cases, respectively, even without clinical suspicion of venous thromboembolism. ${ }^{38,39}$ Acute coronary syndrome/myocardial infarction ${ }^{40,41}$ and strokes ${ }^{42}$ have been associated with critically ill patients. Other events related to macrothromboses have been reported in the bowels $^{43}$ and extremities, ${ }^{44}$ sometimes with important clinical consequences.

Furthermore, COVID-19-related microthrombi are typical. Their discovery began with the suspicion that COVID-19-related acute respiratory distress syndrome, with preserved lung mechanics despite the severity of hypoxemia, occurred due to micro-obstructions in the pulmonary vasculature. ${ }^{45-47}$ Indeed, the acronym MicroCLOTS (microvascular COVID-19 lung vessel obstructive thromboinflammatory syndrome) was suggested as the name for the disease phenotype of acute respiratory distress syndrome/SARS-CoV-2. ${ }^{48}$ Scanning electron micrographs of the pulmonary microvascular bed in patients with COVID-19 exhibited substantial architectural distortion and significant intussusception (a type of neoangiogenesis) related to microvascular occlusion. ${ }^{24}$ Magro et $\mathrm{al}^{47}$ described what is probably the earliest histopathologic event in pulmonary COVID-19: multifocal microthrombotic interstitial pneumonitis accompanied by a slight/moderate intra-alveolar exudate. Other reports also found increased fibrinous thrombi in the pulmonary microcirculation of patients who died of COVID-19. ${ }^{34,49-51}$ However, microvascular damage caused by fibrinous thrombi, endotheliitis, and complement activation was not limited to the lungs but was also described in other organs and tissues: heart, ${ }^{52}$ skin, ${ }^{47,53}$ kidneys, ${ }^{54}$ and small intestine. ${ }^{55}$ Notably, displaced thrombi traveling in the microcirculation of the sublingual region were found in $85 \%$ (11 of 13) of patients with severe COVID-19; four (31\%) exhibited completely stagnated capillaries, and eight $(61 \%)$ showed abrupt interruptions in blood flow, suggesting acute embolism. None of the patients had evidence of disseminated intravascular coagulation. ${ }^{56}$

These findings may indicate that a procoagulant status may be a hallmark event of COVID-19 and suggest that when they spread widely, these microvascular obstructions can promote tissue damage depending on their quantity and/ or the vulnerability of the affected organ. Altogether, these circumstances strongly point to the vascular system on both the macro and micro scales as an important target of COVID-19. ${ }^{57}$ However, other organs and tissues are also severely affected by SARS-CoV-2, leading us to pursue a unifying pathophysiological explanation for the multivariate clinical presentation of this unprecedented infection.

\section{ACE2 Down-Regulation Promoting RAAS Dysregulation}

Knowledge of the underlying biology and physiology of ACE2 has accumulated over the last 20 years since its discovery and has substantially improved our understanding of the RAAS. ${ }^{10-12}$ Because ACE2 contributes critically to the biology of SARS-CoV-2 infection, much attention has been focused on the interplay between COVID-19 and RAAS. ${ }^{58,59}$ The RAAS may also be indirectly involved in the pathophysiology of other respiratory infections, but in SARS-CoV-2 infection, it seems to play an important and direct role in the development and progression of COVID$19 .{ }^{58}$

ACE2 is expressed in almost all human tissues: its expression level is high in the small intestine, testes, adipose tissue, kidneys, heart, and thyroid; medium in the lungs, colon, liver, bladder, and adrenal glands; and relatively low in the blood vessels, spleen, bone marrow, brain, and muscle. ${ }^{5,60}$ ACE2 is expressed as a cell-surface non-raft protein with little intracellular localization, and the protein is not readily internalized. However, binding of a coronavirus $S$ protein to ACE2 triggers enzyme internalization, downregulating its cell surface activity. ${ }^{61}$ Moreover, the viral $\mathrm{S}$ subunit contains a cleavage site for furin and other 


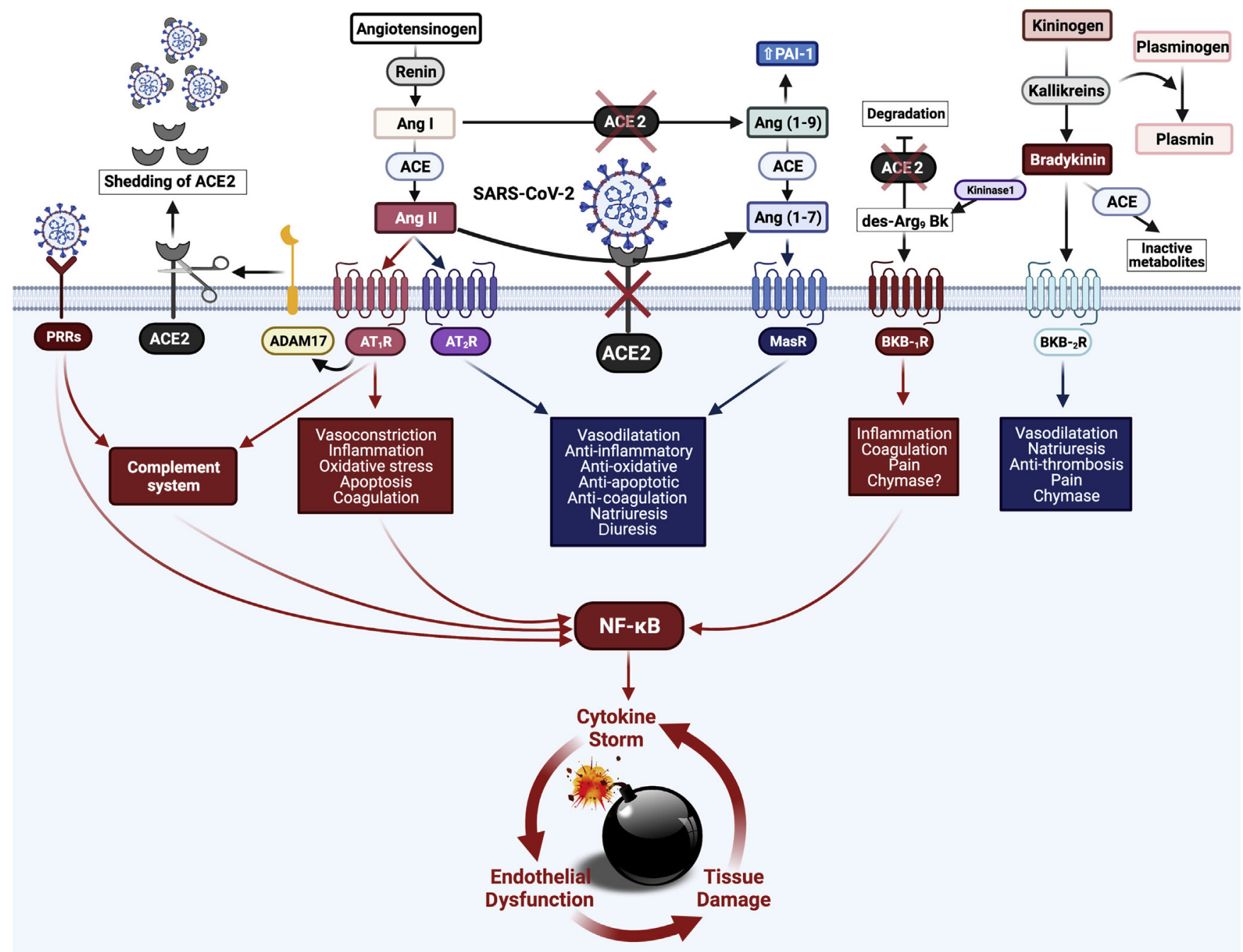

Figure 1 Schematic representation of the dysregulation in the renin-angiotensin-aldosterone system caused by severe acute respiratory syndrome coronavirus 2 (SARS-CoV-2). Renin converts angiotensinogen into angiotensin I (Ang I). Angiotensin-converting enzyme (ACE) converts Ang I into angiotensin II (Ang II), which binds to its receptors Ang II type 1 receptor $\left(A T_{1} R\right)$ and Ang II type 2 receptor $\left(A T_{2} R\right)$. Ang II exerts most of its harmful cardiovascular effects through the ACE/Ang II/AT ${ }_{1} R$ axis. Usually, the major part of Ang II is converted by angiotensin-converting enzyme 2 (ACE2) to become Ang 1-7, which activates the Mas receptor signaling pathway with protective effects in the microcirculatory environment. In coronavirus disease 2019, after the attachment of SARS-CoV-2 spike protein to ACE2, its intracellular binding site down-regulates ACE2. Disintegrin and metalloproteinase domain-containing protein 17 (ADAM17), cleaving the ACE2 terminal, also contributes to the negative regulation of ACE2 by spreading it along with the attached virus through bloodstream. The down-regulation of ACE2 culminates in Ang II upregulation, corroborating to a pro-inflammatory milieu. The kallikrein-kinin system is intensively interwoven with the renin-angiotensin-aldosterone system through many pathways with complex reciprocal interaction metabolites, especially des-Arg ${ }_{9}$ bradykinin (DABK). ACE2 cleaves terminal residue of DABK, resulting in its deactivation. The derangement $A C E 2 / D A B K / b r a d y k i n i n ~ B_{1}$ receptor (BKB- $R$ ) axis activation creates a proinflammatory synergistic effect for SARS-CoV-2 in association with ACE/Ang II/AT ${ }_{1} R$ axis activation. The complement system is activated both by the Ang II/ACE2 axis and by recognizing SARS-CoV-2 by pattern recognition receptors (PRRs). The interaction of ACE2 with the coagulation system is indirect and occurs by inhibiting fibrinolysis. In this context, the NF- $\kappa B$ pathway receives stimuli along three different axes: Ang II/AT ${ }_{1}$, $D A B K /$ $B K B-{ }_{1} R$, and SARS-CoV-2/PRRs/complement. NF- $\kappa B$ hyperactivation then promotes a positive feedback cycle between cytokine storm, endothelial dysfunction, and tissue damage in the microcirculatory environment. BKB- ${ }_{2} \mathrm{R}$, bradykinin $\mathrm{B}_{2}$ receptor; MasR, Ang 1-7 receptor Mas; PAI-1, plasminogen activator inhibitor-1. Created with BioRender.com.

proteases, which accelerates the cellular entry of SARSCoV-2. ${ }^{12}$ In addition to promoting ACE2 internalization, SARS-CoV promotes the enzymatic shedding of the ACE2 ectodomain, resulting in both the generation of a soluble form of ACE2 and an overall reduction in ACE2 content in the infected cells. ${ }^{30}$ Because the S proteins of SARS-CoV-2 and SARS-CoV share $76 \%$ overall amino acid identity and display similar receptor-binding modules, ${ }^{30}$ it is likely that SARS-CoV-2 also induces ACE2 shedding.

ACE2 serves as an endogenous inhibitor of inflammatory signals associated with four major regulator systems: RAAS, the kallikrein-kinin system, the coagulation cascade, and the complement system. ${ }^{12,15,17,61-65}$ ACE2 plays a fundamental role in regulating the RAAS by directly 

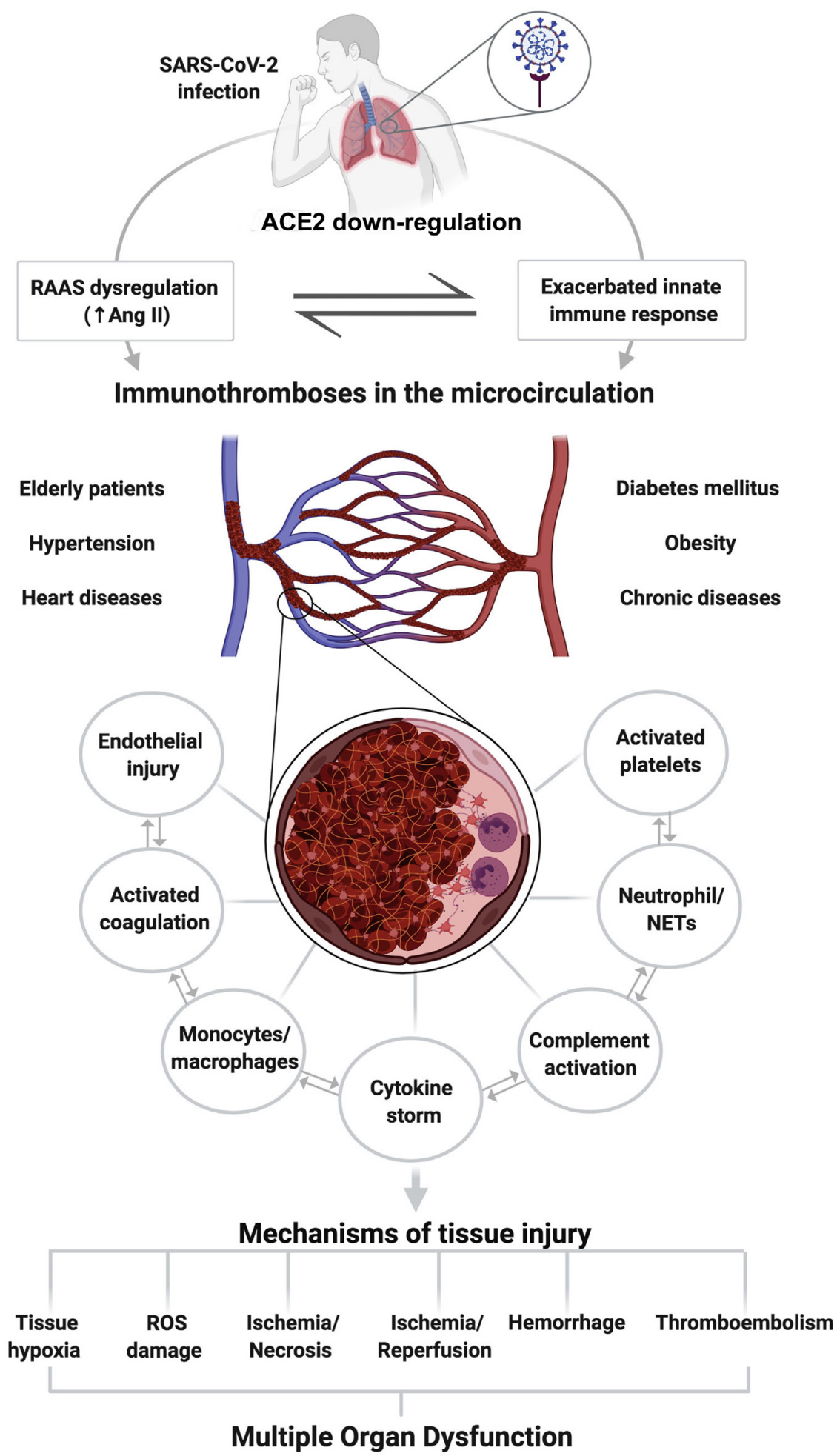

Figure 2 Schematic representation showing the pathologic consequences of negative regulation of angiotensin-converting enzyme 2 (ACE2) in coronavirus disease 19. After entering the body, severe acute respiratory syndrome coronavirus 2 (SARS-CoV-2) infects the alveolar epithelial by engaging ACE2 and promoting its negative regulation. The down-regulation of ACE2 leads to renin-angiotensin-aldosterone system (RAAS) dysregulation, which associated with the exacerbated innate immunity response, favors the appearance of immunothromboses in the microcirculation. These immunothrombi result from the activation of inflammatory and coagulation pathways through a cytokine storm, resulting in endothelial dysregulation, leukocyte activation, neutrophil extracellular trap (NET) generation, complement deposition, and platelet consumption. Pre-existing dysregulation of the RAAS in elderly patients and patients with heart disease, hypertension, diabetes mellitus, chronic diseases, and obesity may contribute to an unfavorable outcome in SARS-CoV-2. Tissue damage can occur through a wide range of mechanisms, including tissue hypoxia, damage by reactive oxygen species (ROS), ischemia/necrosis, ischemia-reperfusion injury, hemorrhage, and/or thromboembolism. These changes, if left untreated, can lead to multiorgan dysfunction and death. Ang II, angiotensin II. Created with BioRender.com (Toronto, Canada). converting Ang II to Ang 1-7., ${ }^{9,10,12,13}$ Ang II is the main vascular effector of the RAAS and exerts its deleterious effects on the cardiovascular system via $\mathrm{AT}_{1} \mathrm{R}$ by activating vasoconstrictor, inflammatory, and fibrotic pathways. Ang II accumulation also activates ADAM17 activity, thus perpetuating membrane shedding of ACE2, RAAS overactivation, and inflammation. ${ }^{12,15,65}$ In addition, after $\mathrm{AT}_{1} \mathrm{R}$ activation, Ang II can activate the NF- $\kappa \mathrm{B}$ pathway $^{66,67}$ via stimulation of the phosphorylation of the p65 subunit of NF- $\kappa$ B. ${ }^{68}$ This action leads to increased production of IL-6, tumor necrosis factor- $\alpha$, IL-1 $\beta$, IL-10, and IL-12. ${ }^{68,69}$ Although Ang II induces vasoconstriction 
and promotes a proinflammatory/prothrombotic phenotype, Ang 1-7 exerts vasodilatory, antiproliferative, anticoagulation, and antifibrotic activity via its specific Mas receptor, thus counterbalancing the adverse effects of Ang II mediated by $\mathrm{AT}_{1} \mathrm{R}^{5,15,61}$ Therefore, Ang 1-7, the main product of ACE2 in the regulation of RAAS, plays a critical role in maintaining microcirculatory balance through the inhibition of proinflammatory and procoagulant pathways. ${ }^{61}$

The kallikrein-bradykinin (BK) system is intensively interwoven with RAAS through many pathways with complex reciprocal interaction metabolites, especially des$\mathrm{Arg}_{9}$-BK (DABK). ${ }^{70} \mathrm{DABK}$ is a known pulmonary inflammatory factor. ${ }^{70,71}$ ACE2 cleaves terminal residue of DABK, resulting in its deactivation. ${ }^{72,73}$ Activation of the derangement $\mathrm{ACE} 2 / \mathrm{DABK} / \mathrm{BK} \mathrm{B}_{1}$ receptor axis creates a proinflammatory synergistic effect for SARS-CoV-2 in association with activation of the ACE/Ang II/AT $T_{1} \mathrm{R}$ axis. ${ }^{15,62,63}$ The resulting effect is a more inflammatory state, neutrophil recruitment, and enhancement of pathologic pulmonary changes in severe COVID-19, including NF- $\kappa B$ activity. ${ }^{62,63}$ The increased production of Ang II and activation of $\mathrm{AT}_{1} \mathrm{R}$ can also occur via activation of the complement cascade, including C5a and C5b-9, indicating cross-talk between the RAAS and the complement system. ${ }^{74}$ Finally, the interaction of ACE2 with the coagulation system is indirect and occurs via two mechanisms: catalyzing the production of Ang 1-9, which reduces plasminogen activator and increases plasminogen activator inhibitor-1, thus inhibiting fibrinolysis, ${ }^{75}$ and modulating the activity of kallikrein, which in turn catalyzes the conversion of plasminogen into plasmin. ${ }^{76}$ Together, these highly integrated pathways certainly contribute to the overproduction of inflammatory mediators, causing a cytokine storm and feeding back a destructive circuit of immunothrombosis and tissue damage in the microcirculatory environment. These events appear to be crucial in the pathogenesis of COVID19. A schema showing the main pathways involving ACE2 down-regulation is shown in Figure 1.

\section{ACE2 Down-Regulation and Tissue Damage: Clinical and Experimental Data}

In a recent study conducted in patients with COVID-19, the viral load and the severity of lung injury were strongly associated with the circulating levels of Ang II. ${ }^{77}$ Moreover, a cohort of 12 patients with COVID-19 showed markedly elevated circulating Ang II levels compared with healthy control subjects (linearly correlated with viral load), providing a direct link between tissue ACE2 downregulation and systemic RAAS imbalance, which favors multiorgan damage from SARS-CoV-2 infection. ${ }^{78}$ Although respiratory symptoms are predominant, acute cardiac and kidney injuries, arrhythmias, cerebral symptoms, and gut and liver function abnormalities are being reported in infected patients. ${ }^{12}$ This finding is relevant to the pulmonary, cardiac, and renal tissues of infected subjects, especially patients with heart failure, diabetes, pulmonary diseases, and hypertension, whose current clinical settings are associated with RAAS dysregulation. ${ }^{72}$ Given these premises, it seems reasonable to speculate that depletion of ACE2 and activation of the ACE/Ang II/AT $\mathrm{R}_{1} \mathrm{R}$ axis might have a pivotal role in the clinical presentations of COVID-19.

Based on experimental models of SARS, virus-induced ACE2 suppression is believed to propagate acute lung injury by leading to increased lung Ang II content. ${ }^{14}$ It was also shown in non-SARS experimental studies. ACE2 knockout mice exhibited acute respiratory distress syndrome/acute lung injury pathology, characterized by increased vascular permeability, increased pulmonary edema, neutrophil accumulation, and deterioration of lung function compared with normal wild-type control mice. ${ }^{14}$ ACE deficiency partially rescued the severe lung injury phenotype of mice that had a single mutation in the ACE2 gene, suggesting that the balance of ACE and ACE2 levels is the key to lung injury or lung protection during an inflammatory storm. ${ }^{79}$ Moreover, the hearts of ACE2 knockout mice exhibited increased Ang II levels and up-regulation of hypoxiainducible genes, suggesting that cardiac function is modulated by the balance between ACE and ACE2 and that the increase in local cardiac Ang II is involved in these abnormalities. This is supported by the fact that the cardiac phenotype and increased Ang II levels were completely reversed by concomitant deletion of the ACE gene in ACE2 knockout mice. ${ }^{61}$ Recent studies suggest that ACE2 influences the electrical pathways of the heart. In ACE2 transgenic mice, cardiac conduction disturbances were present, and some animals developed lethal ventricular fibrillation. ${ }^{80}$ Furthermore, Ang II is increased in damaged tubules, suggesting its possible role as a mediator of renal damage in experimental and human renal disorders. A disrupted balance between intrarenal ACE and ACE2, with consequent high levels of Ang II, might therefore contribute to progressive renal damage. ${ }^{81}$ Collectively, this evidence points to a conceptual framework in which ACE2 is a central player in normal multiorgan functions, and its negative regulation during infection can be a fundamental event producing disease.

\section{COVID-19: A Transient Acquired Regulatory Molecular Disease Causing a Major Problem in the Microcirculatory Environment}

Prof. Ruy Pérez-Tamayo, M.D., Ph.D., a renowned pathologist, stated that when a structurally normal protein is present but its relative concentration in the different compartments of the organism is perturbed in association with corresponding functional changes, the scenario constitutes a molecular disease. Such diseases can be further classified as regulatory (quantitative deviations from the norm) or 
acquired (caused by "toxic substances" and treated by removal of the responsible agent). ${ }^{82}$ Therefore, the current article proposes that COVID-19 be considered an acquired regulatory molecular disease characterized by a transient down-regulation of ACE2 and, consequently RAAS dysregulation, promoting elevated levels of Ang II in the microcirculation, which, in association with the exacerbated innate immunity induced by response of the virus, promotes the spread of immunothrombosis in the microcirculatory system throughout the body.

Immunothrombosis results from the activation of inflammatory pathways through a cytokine storm, resulting in endothelial dysregulation, leukocyte activation, NET generation, complement deposition, and platelet consumption. ${ }^{22,23}$ These powerful pathways require strict regulation to ensure that they are disarmed at the appropriate time and place, and for the appropriate duration. Otherwise, they can become extremely dangerous for the organism that they normally protect. ${ }^{22}$ At least during bacterial infection, immunothromboses appear to involve a limited number of microvessels and often do not result in complete vessel occlusion. ${ }^{18}$ The final extent of organ damage depends, in addition to the primary insult, on the extent of the subsequent microvascular thromboinflammatory response. Unlike thrombosis in the great arteries, thrombosis in the microvessels can result in a relatively diffuse impairment of perfusion and widespread dysfunction of the affected organs. ${ }^{22}$ Taking this in account, it is rational to predict that these inflammatory microthrombi could lead to a wide range of tissue consequences, including tissue hypoxia, damage by reactive oxygen species, ischemia/necrosis, ischemia/reperfusion injury, hemorrhage, and/or systemic thromboembolism. A schematic view, with a summary of the sequence of changes from the entry of SARS-CoV-2 into the lower airways to the possible causes of tissue damage, is shown in Figure 2.

These microthrombi may be especially prominent wherever there are ACE2-positive cells, especially in the lungs, heart, kidneys, brain, and endothelium. ${ }^{58}$ Interestingly, in the pathophysiology of COVID-19, there seems to be enormous spatiotemporal heterogeneity in the involvement of organs. ${ }^{83}$ Therefore, histologic consequences may be aggravated when occurring simultaneously in patients who already have conditions involving a dysregulation of the RAAS, such as heart diseases, hypertension, diabetes mellitus, chronic diseases, older age, and obesity. ${ }^{79,84}$ The damage to the organs will vary depending on the quantity of thrombi, the vulnerability of the tissue, the general conditions of the patient (eg, old age, pre-existing diseases), and genetic conditions (eg, sex, blood type, ethnicity, individual immune response). ${ }^{16}$ Recently, it was proposed that an ACE gene polymorphism, accounting for the differences in ACE levels in the general population, may be responsible for susceptibility to severe lung injury in patients with COVID$19{ }^{85}$ The crude fatality rate of patients with COVID-19 without documented comorbidities is $0.9 \%$, compared with $10.5 \%$ for patients with cardiovascular disease and $7.3 \%$ for patients with diabetes. ${ }^{86}$ All of these considerations suggest the existence of a wide variety of injury mechanisms that can occur in different organs in this disease. Therefore, the better these pathophysiological differences are understood, the more quickly therapies can be developed to target specific organs.

In the initial phase, the virus can enter the peripheral bloodstream via the lungs and may result in viremia. ${ }^{87} \mathrm{It}$ may then proceed to affect other organs expressing ACE2, such as the heart and blood vessels, kidneys, and gastrointestinal tract. In this regard, viral entry via endothelialexpressed ACE2 could represent a mechanism by which the virus can enter and infect other tissues via proteolytic processing and shedding, driving the systemic manifestations of COVID-19. ${ }^{12}$ It is important to remember that the endothelium lines the lumen of the entire circulatory system, from the chambers of the heart to the microcapillary beds, and, quantitatively, approximately $98 \%$ of all endothelial cells reside in the microvasculature, reflecting the vast surface area of the microcirculatory system in the human body. ${ }^{23,88}$ Therefore, endothelial dysfunction may be the major issue in critically ill patients and can lead to the development of multiorgan dysfunction syndrome and death. ${ }^{23}$ The mechanisms of endothelial dysfunction that occur in COVID-19 are not yet fully understood. ${ }^{89-92}$ However, evidence suggests that aberrant immunothrombosis contributes to thrombus formation in large vessel disease, including atherothrombosis and deep venous thromboembolism. ${ }^{93}$ Structural analysis of venous clots revealed activated leukocytes and NETs within the architecture of a thrombus, supporting the involvement of leukocyte-mediated platelet activation and NET-driven venous thromboembolism. ${ }^{94,95}$ Therefore, NETs, further contributing to tissue damage, may be involved in the pathogenesis of venous and arterial thrombosis in COVID19. Unraveling the pathologic basis of COVID-19 is essential for our understanding of the pathophysiology of this intriguing disease.

In the vast majority of conditions defined and/or accompanied by microvascular thrombosis, the diagnosis is typically made clinically and sometimes confirmed histologically, when possible. ${ }^{22}$ Notably, the resolution of a computed tomography angiogram or magnetic resonance angiogram typically does not provide information about the structure of microscopic vessels. ${ }^{22}$ Therefore, microvascular thrombosis likely occurs at a more frequent rate than reported due to difficulty in establishing this diagnosis. To date, there is no specific laboratory surrogate for this entity. Thus, early recognition is typically an important factor in delivering effective therapy.

The interaction between the SARS-CoV-2 S protein and ACE2 has generated abundant and renewed interest in the RAAS. Many in the research community are asking questions regarding whether and how the RAAS modulates SARS-CoV-2 infectivity and COVID-19 morbidity 
and mortality. ${ }^{58,96}$ Therefore, efforts to obtain new clinical and experimental evidence are important to confirm the SARS-CoV-2/ACE2/RAAS interaction and how interventions in this pathway can influence the pathogenesis of COVID-19. Understanding the functions of ACE2 in COVID-19 can help optimize current therapies and, ultimately, guide the development of new therapeutic strategies.

\section{Conclusions}

Emerging data show a crucial role of ACE2 downregulation in SARS-CoV-2 infection, promoting the dysregulation of the RAAS and a consequent increase in the levels of Ang II in the microcirculation, which, in turn, at least in part, creates a proinflammatory and procoagulant state that diffuses immunothromboses and tissue damage in patients with COVID-19.

ACE2 serves as an endogenous inhibitor of inflammatory signals associated with four major regulator systems: the RAAS, the kallikrein-kinin system, the coagulation cascade, and the complement system. Many of these pathways certainly involve the regulation of the RAAS, strengthening the hypothesis that the down-regulation of ACE2 must be crucial in the pathogenesis of COVID-19.

This proposed new concept of COVID-19 as an acquired regulatory molecular disease provides a unifying pathophysiological picture of this infection in all organs, offering a framework for a rational treatment strategy to combat this new pandemic.

Pre-existing dysregulation of the RAAS in old age, heart disease, hypertension, chronic diseases, diabetes mellitus, and obesity combined with macrovascular damage induced by SARS-CoV-2 may contribute to poor outcomes in COVID-19.

The mechanisms of tissue damage in the microcirculatory environment may include tissue hypoxia, reactive oxygen species, ischemia/necrosis, ischemia/reperfusion injury, hemorrhage, and/or systemic thromboembolism. NETs, which further promote tissue damage, are probably involved in the pathogenesis of arterial and venous thrombosis, causing important ischemic events throughout the body.

All these considerations suggest the existence of a wide variety of injury mechanisms, occurring in different organs. A better understanding of these pathophysiological differences in specific organs may be essential for the development of targeted therapies.

Based on mechanistic understanding, certain readily available drugs that act on the expression of ACE2/Ang II should be tested in a well-planned manner to assist in the treatment of COVID-19.

Clinical evidence coupled with novel evidence from basic research is required to confirm how SARS-CoV-2 interacts with and modifies the RAAS and how this interaction may influence COVID-19 pathogenesis.

\section{Acknowledgments}

This work is dedicated to Prof. Marcos A. Rossi (in memoriam), a great pathologist and friend.

\section{Author Contributions}

S.G.R. conceptualized, wrote the original draft, and performed review, editing, and funding acquisition. B.A.d.C.R. conceptualized, wrote the original draft, and authored the illustrations. G.O. and M.R.N.C. led the investigation. E.P.D. performed writing, review, and editing.

\section{References}

1. Wu Z, McGoogan JM: Characteristics of and important lessons from the coronavirus disease 2019 (COVID-19) outbreak in China: summary of a report of 72314 cases from the Chinese Center for Disease Control and Prevention. JAMA 2020, 323:1239-1242

2. Gustine JN, Jones D: Immunopathology of hyperinflammation in COVID-19. Am J Pathol 2021, 191:4-17

3. Walls AC, Xiong X, Park YJ, Tortorici MA, Snijder J, Quispe J, Cameroni E, Gopal R, Dai M, Lanzavecchia A, Zambon M, Rey FA, Corti D, Veesler D: Unexpected receptor functional mimicry elucidates activation of coronavirus fusion. Cell 2019, 176:1026-1039

4. Ziegler CGK, Allon SJ, Nyquist SK, Mbano IM, Miao VN, Tzouanas CN, et al: SARS-CoV-2 receptor ACE2 is an interferonstimulated gene in human airway epithelial cells and is detected in specific cell subsets across tissues. Cell 2020, 181:1016-1035.e19

5. Verdecchia P, Cavallini C, Spanevello A, Angeli F: COVID-19: ACE2centric infective disease? Hypertension 2020, 76:294-299

6. Sfera A, Osorio C, Jafri N, Diaz EL, Campo Maldonado JE: Intoxication with endogenous angiotensin II: a COVID-19 hypothesis. Front Immunol 2020, 11:1472

7. Heurich A, Hofmann-Winkler H, Gierer S, Liepold T, Jahn O, Pöhlmann S: TMPRSS2 and ADAM17 cleave ACE2 differentially and only proteolysis by TMPRSS2 augments entry driven by the severe acute respiratory syndrome coronavirus spike protein. J Virol 2014, 88:1293-1307

8. Liu Y, Gayle AA, Wilder-Smith A, Rocklöv J: The reproductive number of COVID-19 is higher compared to SARS coronavirus. J Travel Med 2020, 27:taaa021

9. Tipnis SR, Hooper NM, Hyde R, Karran E, Christie G, Turner AJ: A human homolog of angiotensin-converting enzyme. Cloning and functional expression as a captopril-insensitive carboxypeptidase. J Biol Chem 2000, 275:33238-33243

10. Donoghue M, Hsieh F, Baronas E, Godbout K, Gosselin M, Stagliano N, Donovan M, Woolf B, Robison K, Jeyaseelan R, Breitbart RE, Acton S: A novel angiotensin-converting enzymerelated carboxypeptidase (ACE2) converts angiotensin I to angiotensin 1-9. Circ Res 2000, 87:E1-E9

11. Oudit GY, Crackower MA, Backx PH, Penninger JM: The role of ACE2 in cardiovascular physiology. Trends Cardiovasc Med 2003, $13: 93-101$

12. Gheblawi M, Wang K, Viveiros A, Nguyen Q, Zhong JC, Turner AJ, Raizada MK, Grant MB, Oudit GY: Angiotensin-converting enzyme 2: SARS-CoV-2 receptor and regulator of the renin-angiotensin system: celebrating the 20th anniversary of the discovery of ACE2. Circ Res 2020, 126:1456-1474

13. Luft FC: Tissue renin-angiotensin system and end-organ damage. J Mol Med 2002, 80:325-326 
14. Kuba K, Imai Y, Rao S, Gao H, Guo F, Guan B, Huan Y, Yang P, Zhang Y, Deng W, Bao L, Zhang B, Liu G, Wang Z, Chappell M, Liu Y, Zheng D, Leibbrandt A, Wada T, Slutsky AS, Liu D, Qin C, Jiang C, Penninger JM: A crucial role of angiotensin converting enzyme 2 (ACE2) in SARS coronavirus-induced lung injury. Nat Med 2005, 11:875-879

15. Mahmudpour M, Roozbeh J, Keshavarz M, Farrokhi S, Nabipour I: COVID-19 cytokine storm: the anger of inflammation. Cytokine 2020, 133:e155151

16. Labò N, Ohnuki H, Tosato G: Vasculopathy and coagulopathy associated with SARS-CoV-2 infection. Cells 2020, 9:1583

17. Curran CS, Rivera DR, Kopp JB: COVID-19 usurps host regulatory networks. Front Pharmacol 2020, 11:1278

18. Engelmann B, Massberg S: Thrombosis as an intravascular effector of innate immunity. Nat Rev Immunol 2013, 13:34-45

19. Delvaeye M, Conway EM: Coagulation and innate immune responses: can we view them separately? Blood 2009, 114:2367-2374

20. Massberg S, Grahl L, von Bruehl ML, Manukyan D, Pfeiler S, Goosmann C, Brinkmann V, Lorenz M, Bidzhekov K, Khandagale AB, Konrad I, Kennerknecht E, Reges K, Holdenrieder S, Braun S, Reinhardt C, Spannagl M, Preissner KT, Engelmann B: Reciprocal coupling of coagulation and innate immunity via neutrophil serine proteases. Nat Med 2010, 16:887-896

21. Radermecker C, Detrembleur N, Guiot J, Cavalier E, Henket M, d'Emal C, Vanwinge C, Cataldo D, Oury C, Delvenne P, Marichal T: Neutrophil extracellular traps infiltrate the lung airway, interstitial, and vascular compartments in severe COVID-19. J Exp Med 2020, 217:e20201012

22. Bray MA, Sartain SE, Gollamudi J, Rumbaut RE: Microvascular thrombosis: experimental and clinical implications. Transl Res 2020, 225:105-130

23. Jackson SP, Darbousset R, Schoenwaelder SM: Thromboinflammation: challenges of therapeutically targeting coagulation and other host defense mechanisms. Blood 2019, 133:906-918

24. Ackermann M, Verleden SE, Kuehnel M, Haverich A, Welte T, Laenger F, Vanstapel A, Werlein C, Stark H, Tzankov A, Li WW, Li VW, Mentzer SJ, Jonigk D: Pulmonary vascular endothelialitis, thrombosis, and angiogenesis in Covid-19. N Engl J Med 2020, 383: $120-128$

25. McFadyen JD, Stevens H, Peter K: The emerging threat of (micro) thrombosis in COVID-19 and its therapeutic implications. Circ Res 2020, 127:571-587

26. Ye Q, Wang B, Mao J: The pathogenesis and treatment of the "cytokine storm' in COVID-19. J Infect 2020, 80:607-613

27. Tay MZ, Poh CM, Rénia L, MacAry PA, Ng LFP: The trinity of COVID-19: immunity, inflammation and intervention. Nat Rev Immunol 2020, 20:363-374

28. Barnes BJ, Adrover JM, Baxter-Stoltzfus A, Borczuk A, CoolsLartigue J, Crawford JM, Daßler-Plenker J, Guerci P, Huynh C, Knight JS, Loda M, Looney MR, McAllister F, Rayes R, Renaud S, Rousseau S, Salvatore S, Schwartz RE, Spicer JD, Yost CC, Weber A, Zuo Y, Egeblad M: Targeting potential drivers of COVID-19: neutrophil extracellular traps. J Exp Med 2020, 217: e20200652

29. Fletcher-Sandersjöö A, Bellander BM: Is COVID-19 associated thrombosis caused by overactivation of the complement cascade? A literature review. Thromb Res 2020, 194:36-41

30. Jaimes JA, André NM, Chappie JS, Millet JK, Whittaker GR: Phylogenetic analysis and structural modeling of SARS-CoV-2 spike protein reveals an evolutionary distinct and proteolytically sensitive activation loop. J Mol Biol 2020, 432:3309-3325

31. Jayarangaiah A, Kariyanna PT, Chen X, Jayarangaiah A, Kumar A: COVID-19-associated coagulopathy: an exacerbated immunothrombosis response. Clin Appl Thromb Hemost 2020, 26. 1076029620943293

32. Veras FP, Pontelli MC, Silva CM, Toller-Kawahisa JE, de Lima M, Nascimento DC, et al: SARS-CoV-2 triggered neutrophil extracellular traps mediate COVID-19 pathology. J Exp Med 2020, 217:e20201129

33. Ruan Q, Yang K, Wang W, Jiang L, Song J: Clinical predictors of mortality due to COVID-19 based on an analysis of data of 150 patients from Wuhan, China. Intensive Care Med 2020, 46:846-848

34. Leppkes M, Knopf J, Naschberger E, Lindemann A, Singh J, Herrmann I, Stürzl M, Staats L, Mahajan A, Schauer C, Kremer AN, Völkl S, Amann K, Evert K, Falkeis C, Wehrfritz A, Rieker RJ, Hartmann A, Kremer AE, Neurath MF, Muñoz LE, Schett G, Herrmann M: Vascular occlusion by neutrophil extracellular traps in COVID-19. EBioMedicine 2020, 58:102925

35. Iba T, Levy JH, Levi M, Connors JM, Thachil J: Coagulopathy of coronavirus disease 2019. Crit Care Med 2020, 48:1358-1364

36. Rodriguez-Morales AJ, Cardona-Ospina JA, Gutiérrez-Ocampo E, Villamizar-Peña R, Holguin-Rivera Y, Escalera-Antezana JP, Alvarado-Arnez LE, Bonilla-Aldana DK, Franco-Paredes C, HenaoMartinez AF, Paniz-Mondolfi A, Lagos-Grisales GJ, RamírezVallejo E, Suárez JA, Zambrano LI, Villamil-Gómez WE, BalbinRamon GJ, Rabaan AA, Harapan H, Dhama K, Nishiura H, Kataoka H, Ahmad T, Sah R; Latin American Network of Coronavirus 2019-COVID-19 Research (LANCOVID-19): Clinical, laboratory and imaging features of COVID-19: a systematic review and meta-analysis. Travel Med Infect Dis 2020, 34:101623

37. Klok FA, Kruip MJHA, van der Meer NJM, Arbous MS, Gommers D, Kant KM, Kaptein FHJ, van Paassen J, Stals MAM, Huisman MV, Endeman H: Confirmation of the high cumulative incidence of thrombotic complications in critically ill ICU patients with COVID-19: an updated analysis. Thromb Res 2020, 191:148-150

38. Wichmann D, Sperhake JP, Lütgehetmann M, Steurer S, Edler C, Heinemann A, Heinrich F, Mushumba H, Kniep I, Schröder AS, Burdelski C, de Heer G, Nierhaus A, Frings D, Pfefferle S, Becker H, Bredereke-Wiedling $\mathrm{H}$, de Weerth A, Paschen HR, SheikhzadehEggers S, Stang A, Schmiedel S, Bokemeyer C, Addo MM, Aepfelbacher M, Püschel K, Kluge S: Autopsy findings and venous thromboembolism in patients with COVID-19: a prospective cohort study. Ann Intern Med 2020, 173:268-277

39. Lax SF, Skok K, Zechner P, Kessler HH, Kaufmann N, Koelblinger C, Vander K, Bargfrieder U, Trauner M: Pulmonary arterial thrombosis in COVID-19 with fatal outcome: results from a prospective, single-center, clinicopathologic case series. Ann Intern Med 2020, 173:350-361

40. Hadid T, Kafri Z, Al-Katib A: Coagulation and anticoagulation in COVID-19. Blood Rev 2020, 47:e100761

41. Amirfakhryan H, Safari F: Outbreak of SARS-CoV2: pathogenesis of Infection and Cardiovascular Involvement. Hellenic J Cardiol 2021, 62:13-23

42. Qi X, Keith KA, Huang JH: COVID-19 and stroke: a review. Brain Hemorrhages 2020, 14:337-339

43. Bhayana R, Som A, Li MD, Carey DE, Anderson MA, Blake MA, Catalano O, Gee MS, Hahn PF, Harisinghani M, Kilcoyne A, Lee SI, Mojtahed A, Pandharipande PV, Pierce TT, Rosman DA, Saini S, Samir AE, Simeone JF, Gervais DA, Velmahos G, Misdraji J, Kambadakone A: Abdominal imaging findings in COVID-19: preliminary observations. Radiology 2020, 297: E207-E215

44. Calvão J, Relvas M, Pinho A, Brinca A, Cardoso JC: Acro-ischaemia and COVID-19 infection: clinical and histopathological features. J Eur Acad Dermatol Venereol 2020, 34:e653-e754

45. Zhou F, Yu T, Du R, Fan G, Liu Y, Liu Z, Xiang J, Wang Y, Song B, Gu X, Guan L, Wei Y, Li H, Wu X, Xu J, Tu S, Zhang Y, Chen H, Cao B: Clinical course and risk factors for mortality of adult inpatients with COVID-19 in Wuhan, China: a retrospective cohort study. Lancet 2020, 395:1054-1062

46. Gattinoni L, Coppola S, Cressoni M, Busana M, Rossi S, Chiumello D: COVID-19 does not lead to a "typical" acute respiratory distress syndrome. Am J Respir Crit Care Med 2020, 201: $1299-1300$ 
47. Magro C, Mulvey JJ, Berlin D, Nuovo G, Salvatore S, Harp J, BaxterStoltzfus A, Laurence J: Complement associated microvascular injury and thrombosis in the pathogenesis of severe COVID-19 infection: a report of five cases. Transl Res 2020, 220:1-13

48. Ciceri F, Beretta L, Scandroglio AM, Colombo S, Landoni G, Ruggeri A, Peccatori J, D'Angelo A, de Cobelli F, Rovere-Querini P, Tresoldi M, Dagna L, Zangrillo A: Microvascular COVID-19 lung vessels obstructive thromboinflammatory syndrome (MicroCLOTS): an atypical acute respiratory distress syndrome working hypothesis. Crit Care Resusc 2020, 22:95-97

49. Fox SE, Akmatbekov A, Harbert JL, Li G, Quincy Brown J, Vander Heide RS: Pulmonary and cardiac pathology in African American patients with COVID-19: an autopsy series from New Orleans. Lancet Respir Med 2020, 8:681-686

50. Dolhnikoff M, Duarte-Neto AN, de Almeida Monteiro RA, da Silva LFF, de Oliveira EP, Saldiva PHN, Mauad T, Negri EM: Pathological evidence of pulmonary thrombotic phenomena in severe COVID-19. J Thromb Haemost 2020, 18:1517-1519

51. Carsana L, Sonzogni A, Nasr A, Rossi RS, Pellegrinelli A, Zerbi P, Rech R, Colombo R, Antinori S, Corbellino M, Galli M, Catena E, Tosoni A, Gianatti A, Nebuloni M: Pulmonary post-mortem findings in a series of COVID-19 cases from northern Italy: a two-centre descriptive study. Lancet Infect Dis 2020, 20:1135-1140

52. Buja LM, Wolf DA, Zhao B, Akkanti B, McDonald M, Lelenwa L, Reilly N, Ottaviani G, Elghetany MT, Trujillo DO, Aisenberg GM, Madjid M, Kar B: The emerging spectrum of cardiopulmonary pathology of the coronavirus disease 2019 (COVID-19): report of 3 autopsies from Houston, Texas, and review of autopsy findings from other United States cities. Cardiovasc Pathol 2020, 48:107233

53. Colmenero I, Santonja C, Alonso-Riaño M, Noguera-Morel L, Hernández-Martín A, Andina $\mathrm{D}$, Wiesner $\mathrm{T}$, Rodríguez-Peralto JL, Requena L, Torrelo A: SARS-CoV-2 endothelial infection causes COVID-19 chilblains: histopathological, immunohistochemical and ultrastructural study of seven paediatric cases. Br J Dermatol 2020, 183:729-737

54. Cheng Y, Luo R, Wang K, Zhang M, Wang Z, Dong L, Li J, Yao Y, Ge S, Xu G: Kidney disease is associated with in-hospital death of patients with COVID-19. Kidney Int 2020, 97:829-838

55. Varga Z, Flammer AJ, Steiger P, Haberecker M, Andermatt R, Zinkernagel AS, Mehra MR, Schuepbach RA, Ruschitzka F, Moch H: Endothelial cell infection and endotheliitis in COVID-19. Lancet 2020, 395:1417-1418

56. do Espírito Santo DA, Lemos ACB, Miranda CH: In vivo demonstration of microvascular thrombosis in severe COVID-19. J Thromb Thrombolysis 2020, 50:790-794

57. Siddiqi HK, Libby P, Ridker PM: COVID-19-a vascular disease. Trends Cardiovasc Med 2021, 31:1-5

58. Sparks MA, South AM, Badley AD, Baker-Smith CM, Batlle D, Bozkurt B, Cattaneo R, Crowley SD, Dell'Italia LJ, Ford AL, Griendling K, Gurley SB, Kasner SE, Murray JA, Nath KA, Pfeffer MA, Rangaswami J, Taylor WR, Garovic VD: Severe acute respiratory syndrome coronavirus 2, COVID-19, and the reninangiotensin system: pressing needs and best research practices. Hypertension 2020, 76:1350-1367

59. Sarzani R, Giulietti F, De Pentima C, Giordano P, Spannella F: Disequilibrium between the classic renin-angiotensin system and its opposing arm in SARS-CoV-2-related lung injury. Am J Physiol Lung Cell Mol Physiol 2020, 319:L325-L336

60. Li MY, Li L, Zhang Y, Wang XS: Expression of the SARS-CoV-2 cell receptor gene ACE2 in a wide variety of human tissues. Infect Dis Poverty 2020, 9:45

61. Hamming I, Cooper ME, Haagmans BL, Hooper NM, Korstanje R, Osterhaus ADME, Timens W, Turner AJ, Navis G, van Goor H: The emerging role of ACE2 in physiology and disease. J Pathol 2007, 212:1-11

62. Sidarta-Oliveira D, Jara CP, Ferruzzi AJ, Skaf MS, Velander WH, Araujo EP, Velloso LA: SARS-CoV-2 receptor is co-expressed with elements of the kinin-kallikrein, renin-angiotensin and coagulation systems in alveolar cells. Sci Rep 2020, 10:19522

63. Abassi Z, Skorecki K, Hamo-Giladi DB, Kruzel-Davila E, Heyman SN: Kinins and chymase: the forgotten components of the renin angiotensin system and their implications in COVID-19 disease. Am J Physiol Cell Mol Physiol 2021, 320:L422-L429

64. Patel VB, Clarke N, Wang Z, Fan D, Parajuli N, Basu R, Putko B, Kassiri Z, Turner AJ, Oudit GY: Angiotensin II induced proteolytic cleavage of myocardial ACE2 is mediated by TACE/ADAM-17: a positive feedback mechanism in the RAS. J Mol Cell Cardiol 2014, $66: 167-176$

65. Ruiz-Ortega M, Lorenzo O, Suzuki Y, Rupérez M, Egido J: Proinflammatory actions of angiotensins. Curr Opin Nephrol Hypertens 2001, 10:321-329

66. Jamaluddin M, Meng T, Sun J, Boldogh I, Han Y, Brasier AR: Angiotensin II induces nuclear factor (NF)-kappaB1 isoforms to bind the angiotensinogen gene acute-phase response element: a stimulusspecific pathway for NF-kappaB activation. Mol Endocrinol 2000, 14:99-113

67. Skurk T, van Harmelen V, Hauner H: Angiotensin II stimulates the release of interleukin- 6 and interleukin- 8 from cultured human adipocytes by activation of NF-kappaB. Arterioscler Thromb Vasc Biol 2004, 24:1199-1203

68. Sano M, Fukuda K, Kodama H, Pan J, Saito M, Matsuzaki J, Takahashi T, Makino S, Kato T, Ogawa S: Interleukin-6 family of cytokines mediate angiotensin II-induced cardiac hypertrophy in rodent cardiomyocytes. J Biol Chem 2000, 275: 29717-29723

69. Mehta PK, Griendling KK: Angiotensin II cell signaling: physiological and pathological effects in the cardiovascular system. Am J Physiol Cell Physiol 2007, 292:C82-C97

70. Dong C, Davis RJ, Flavell RA: MAP kinases in the immune response. Annu Rev Immunol 2002, 20:55-72

71. Arthur JSC, Ley SC: Mitogen-activated protein kinases in innate immunity. Nat Rev Immunol 2013, 13:679-692

72. Abassi Z, Assady S, Khoury EE, Heyman SN: Letter to the editor: angiotensin-converting enzyme 2: an ally or a Trojan horse? Implications to SARS-CoV-2-related cardiovascular complications. Am J Physiol Heart Circ Physiol 2020, 318:H1080-H1083

73. Feng J, Chen Y, Xiong J, Chen X, Liang J, Ji W: The kinin B1 receptor mediates alloknesis in a murine model of inflammation. Neurosci Lett 2014, 560:31-35

74. Van Laecke S, Van Biesen W: Severe hypertension with renal thrombotic microangiopathy: what happened to the usual suspect? Kidney Int 2017, 91:1271-1274

75. Mogielnicki A, Kramkowski K, Hermanowicz JM, Leszczynska A, Przyborowski K, Buczko W: Angiotensin-(1-9) enhances stasisinduced venous thrombosis in the rat because of the impairment of fibrinolysis. J Renin Angiotensin Aldosterone Syst 2014, 15:13-21

76. Fischer C, Lamer T, Wang W, McKinnie SMK, Iturrioz X, LlorensCortes C, Oudit GY, Vederas JC: Plasma kallikrein cleaves and inactivates apelin-17: palmitoyl- and PEG-extended apelin-17 analogs as metabolically stable blood pressure-lowering agents. Eur J Med Chem 2019, 166:119-124

77. Wu Z, Hu R, Zhang C, Ren W, Yu A, Zhou X: Elevation of plasma angiotensin II level is a potential pathogenesis for the critically ill COVID-19 patients. Crit Care 2020, 24:290

78. Liu Y, Yang Y, Zhang C, Huang F, Wang F, Yuan J, Wang Z, Li J, Li J, Feng C, Zhang Z, Wang L, Peng L, Chen L, Qin Y, Zhao D, Tan S, Yin L, Xu J, Zhou C, Jiang C, Liu L: Clinical and biochemical indexes from 2019-nCoV infected patients linked to viral loads and lung injury. Sci China Life Sci 2020, 63:364-374

79. Imai Y, Kuba K, Rao S, Huan Y, Guo F, Guan B, Yang P, Sarao R, Wada T, Leong-Poi H, Crackower MA, Fukamizu A, Hui CC, Hein L, Uhlig S, Slutsky AS, Jiang C, Penninger JM: Angiotensinconverting enzyme 2 protects from severe acute lung failure. Nature 2005, 436:112-116 
80. Donoghue $\mathrm{M}$, Wakimoto $\mathrm{H}$, Maguire $\mathrm{CT}$, Acton $\mathrm{S}$, Hales $\mathrm{P}$, Stagliano N, Fairchild-Huntress V, Xu J, Lorenz JN, Kadambi V, Berul CI, Breitbart RE: Heart block, ventricular tachycardia, and sudden death in ACE2 transgenic mice with downregulated connexins. J Mol Cell Cardiol 2003, 35:1043-1053

81. Wolf G, Ritz E: Combination therapy with ACE inhibitors and angiotensin II receptor blockers to halt progression of chronic renal disease: pathophysiology and indications. Kidney Int 2005, 67: 799-812

82. Pérez-Tamayo R: Mechanisms of Disease: An Introduction to Pathology. ed 2. Chicago, IL:, Year Book Medical Publishers, Inc., 1985. pp. 16-19

83. Bourgonje AR, Abdulle AE, Timens W, Hillebrands JL, Navis GJ, Gordijn SJ, Bolling MC, Dijkstra G, Voors AA, Osterhaus ADME, van der Voort PHJ, Mulder DJ, van Goor H: Angiotensin-converting enzyme 2 (ACE2), SARS-CoV-2 and the pathophysiology of coronavirus disease 2019 (COVID-19). J Pathol 2020, 251: $228-248$

84. Guan WJ, Ni ZY, Hu Y, Liang WH, Ou CQ, He JX, et al: Clinical characteristics of coronavirus disease 2019 in China. N Engl J Med 2020, 382:1708-1720

85. Zheng H, Cao JJ: Angiotensin-converting enzyme gene polymorphism and severe lung injury in patients with coronavirus disease 2019. Am J Pathol 2020, 190:2013-2017

86. Dan S, Pant M, Upadhyay SK: The case fatality rate in COVID-19 patients with cardiovascular disease: global health challenge and paradigm in the current pandemic. Curr Pharmacol Rep 2020, 6:315-324
87. Jin Y, Ji W, Yang H, Chen S, Zhang W, Duan G: Endothelial activation and dysfunction in COVID-19: from basic mechanisms to potential therapeutic approaches. Signal Transduct Target Ther 2020, 5:293

88. Aird WC: Spatial and temporal dynamics of the endothelium. J Thromb Haemost 2005, 3:1392-1406

89. Hang W, Chen C, Zhang XA, Wang DW: Endothelial dysfunction in COVID-19 calls for immediate attention: the emerging roles of the endothelium in inflammation caused by SARS-CoV-2. Front Med 2021, [Epub ahead of print]. doi:10.1007/s11684-021-0831-z

90. Esmon CT: The interactions between inflammation and coagulation. Br J Haematol 2005, 131:417-430

91. Rinder HM, Bonan JL, Rinder CS, Ault KA, Smith BR: Dynamics of leukocyte-platelet adhesion in whole blood. Blood 1991, 78: $1730-1737$

92. Bernard I, Limonta D, Mahal LK, Hobman TC: Endothelium infection and dysregulation by SARS-CoV-2: evidence and caveats in COVID-19. Viruses 2020, 13:29

93. Levi M, Schultz M, van der Poll T: Sepsis and thrombosis. Semin Thromb Hemost 2013, 39:559-566

94. Swystun LL, Liaw PC: The role of leukocytes in thrombosis. Blood 2016, 128:753-762

95. Gaertner F, Massberg S: Blood coagulation in immunothrombosis - at the frontline of intravascular immunity. Semin Immunol 2016, 28:561-569

96. Chaudhry F, Lavandero S, Xie X, Sabharwal B, Zheng YY, Correa A, Narula J, Levy P: Manipulation of ACE2 expression in COVID-19. Open Heart 2020, 7:e001424 